\title{
DWI for Monitoring the Acute Response of Malignant Gliomas to Photodynamic Therapy
}

\author{
(D) Y. Fujita, (D) T. Sasayama, (D) K. Tanaka, (D). Kyotani, (D) H. Nagashima, (D) M. Kohta, (D) H. Kimura, (D) A. Fujita, and (D) E. Kohmura
}

\begin{abstract}
BACKGROUND AND PURPOSE: Photodynamic therapy is a novel treatment that provides effective local control, but little is known about photodynamic therapy-induced changes on MR imaging. The aim of this study was to assess the utility of DWI and ADC in monitoring the response of malignant gliomas to photodynamic therapy.
\end{abstract}

MATERIALS AND METHODS: Time-dependent changes in DWI and ADC values after photodynamic therapy were analyzed in a group that received photodynamic therapy in comparison with a group that did not.

RESULTS: Twenty-four patients were enrolled (photodynamic therapy, $n=14$; non-photodynamic therapy, $n=10$ ). In all patients who received photodynamic therapy, linear high signals on DWI in the irradiated area were detected adjacent to the resection cavity and were $5-7 \mathrm{~mm}$ in depth from 1 day posttreatment and disappeared in about 30 days without any neurologic deterioration. The non-photodynamic therapy group did not show this change. The photodynamic therapy group had significantly lower ADC values from 1 day posttreatment $(P<.001)$, which increased steadily and disappeared by 30 days. There was no decline or time-dependent change in ADC values in the non-photodynamic therapy group.

CONCLUSIONS: The acute response of malignant gliomas to photodynamic therapy was detected as linear high signals on DWI and as a decrease in ADC values. These findings were asymptomatic and transient. Although the photodynamic therapy-induced acute response on MR imaging disappeared after approximately 30 days, it may be helpful for confirming the photodynamic therapy-irradiated area.

ABBREVIATIONS: $\mathrm{CE}=$ contrast-enhanced; $\mathrm{PDT}$ = photodynamic therapy

S tandard therapy for malignant glioma, the most aggressive primary malignant brain tumor, includes maximal possible surgical resection followed by radiation therapy and concomitant temozolomide-based chemotherapy, which results in a median survival of 14.6 months. ${ }^{1}$ The major problem with malignant glioma is its invasiveness. It is extremely difficult to remove all the tumor cells that have invaded the peripheral normal brain tissue.

Received August 5, 2019; accepted after revision September 13

From the Department of Neurosurgery (Y.F., T.S., K.T., M.K., H.K., A.F., E.K.), Kobe University Graduate School of Medicine, Kobe, Hyogo, Japan; Center for Radiology and Radiation Oncology (K.K.), Kobe University Graduate School of Medicine and Kobe University Hospital, Kobe, Hyogo, Japan; and Department of Neurosurgery (H.N.), Massachusetts General Hospital Research Institute, Boston, Massachusetts.

This work was supported, in part, by a Grant-in-Aid for Scientific Research to Kazuhiro Tanaka (17K10864) and Takashi Sasayama (17K10863) from the Japanese Ministry of Education, Culture, Sports, Science and Technology.

Please address correspondence to Takashi Sasayama, MD, Department of Neurosurgery, Kobe University Graduate School of Medicine, 7-5-1 Kusunoki-cho, Chuo-ku, Kobe, Hyogo 650-0017, Japan; e-mail: takasasa@med.kobe-u.ac.jp

- Indicates open access to non-subscribers at www.ajnr.org

http://dx.doi.org/10.3174/ajnr.A6300
Consequently, local recurrence develops in many cases. ${ }^{2,3}$ Development of novel treatments that have both potency and high selectivity for tumor cells in the peripheral zone where normal brain cells and tumor cells coexist is desirable. Photodynamic therapy (PDT) is a novel treatment that could overcome these issues.

PDT is a light-activated treatment technique that harnesses tumor-selective accumulation of photosensitizer and a photochemical reaction on semiconductor laser irradiation. The oxygen in the tumor tissue is converted from the ground state to the excited state, singlet oxygen, which is cytotoxic and exerts an antitumor effect. ${ }^{4}$ The concept of PDT was first reported in $1900,{ }^{5}$ developed as a treatment technique in the $1960 \mathrm{~s},{ }^{6,7}$ and entered into clinical trials for several types of cancer during the 1980s and 1990s. ${ }^{8-13}$ The potential use of PDT for brain tumors was first reported in 1980, ${ }^{14}$ and its effectiveness with porfimer sodium, a first-generation photosensitizer, for malignant brain tumors was reported in the 2000s. ${ }^{15-17}$ In 2013, the safety and effectiveness of PDT with talaporfin sodium, a second-generation photosensitizer, for primary malignant brain tumors was established in a Phase II clinical trial in Japan. PDT for malignant 


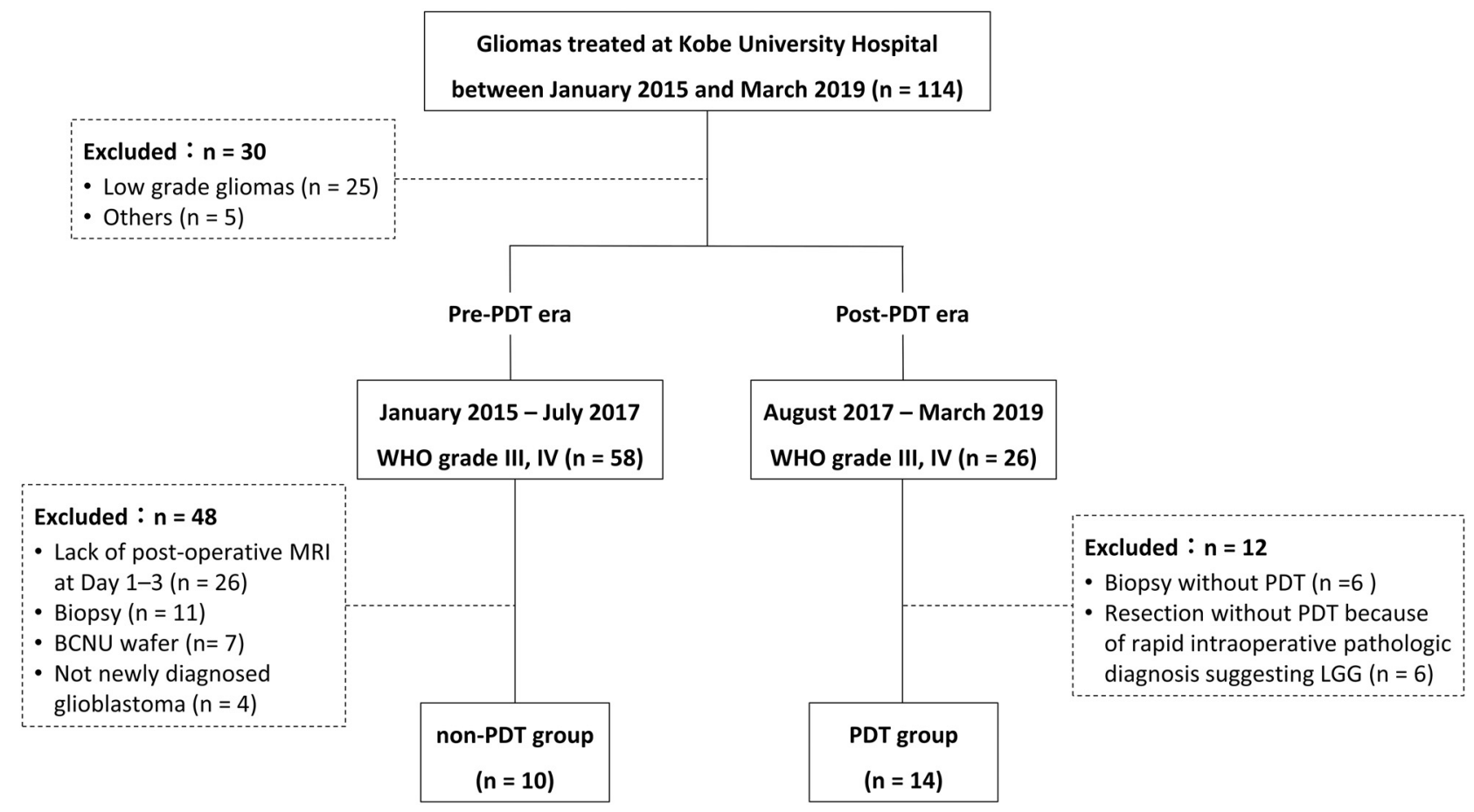

FIG 1. Flow chart showing the patient selection process. LGG indicates low-grade glioma; BCNU, biodegradable carmustine.

brain tumors was subsequently approved for coverage under Japanese national health insurance. ${ }^{18}$

Postoperative follow-up is generally performed using MR imaging. Although a contrast effect in the resected cavity wall and fluid retention have been reported to be transient MR imaging abnormalities after PDT, ${ }^{19}$ these changes can also occur after conventional brain tumor surgery. ${ }^{20}$ It is unclear how purely PDT-induced changes in the tumor microenvironment are reflected on postoperative imaging. Therefore, it would be useful to clarify the characteristic changes on MR imaging after PDT to monitor the therapeutic response. Given the evidence for DWI and ADC in ischemic stroke, ${ }^{21-23}$ we hypothesized that post-PDT changes in brain tumors could be captured by DWI and ADC. The aim of this study was to elucidate the changes on MR imaging that are purely attributable to PDT for malignant glioma to test this hypothesis.

\section{MATERIALS AND METHODS Study Design and Study Patients}

The study was approved by the institutional review board (Kobe University Hospital) (protocol number B190100) and conducted according to institutional and national ethical guidelines and in accordance with the Helsinki Declaration.

Since August 2017, our institution has used PDT in combination with conventional surgery without a biodegradable carmustine wafer in patients with World Health Organization grade III or IV glioma confirmed by rapid intraoperative pathologic diagnosis who underwent $>90 \%$ (gross-total or subtotal) resection or intentional partial resection because of involvement of eloquent areas. Between January 2015 and March 2019, eighty-four of 114 patients with glioma treated at our institution were confirmed histopathologically to have World Health Organization grade III or IV glioma. Twenty-six of these 84 patients were treated during our post-PDT era, from August 2017 to March 2019. Fourteen of these patients underwent PDT and were enrolled in this study as the PDT group; the remaining 12 patients were excluded because they had undergone biopsy without PDT $(n=6)$ or resection without PDT because of an intraoperative pathologic diagnosis suggesting low-grade glioma $(n=6)$. We analyzed the post-PDT time-dependent changes on DWI, in ADC values, and on contrastenhanced T1WI (CE-T1WI) and T2-weighted FLAIR images obtained on days $1,7,14,30$, and 60 after the operation. Furthermore, to confirm whether the findings were specific for PDT, we compared the PDT group with a non-PDT group selected using the following criteria: newly diagnosed glioblastoma treated without PDT and without a biodegradable carmustine wafer at our institution during the pre-PDT era from January 2015 to July $2017,>90 \%$ resection or intentional partial resection because of involvement of eloquent areas, and adequate MR imaging scans obtained at least once during each of the following periods: 13 days, 14-30 days, and 60 days after the operation. Of the 58 patients with World Health Organization grade III or IV glioma treated during the pre-PDT era, 10 met the inclusion criteria and were selected as the non-PDT group and 48 were excluded because of lack of postoperative MR imaging at $1-3$ days $(n=26)$, biopsy $(n=11)$, surgery with a biodegradable carmustine wafer $(n=7)$, or not having a newly diagnosed glioblastoma $(n=4)$. The flow chart outlining the patient-selection process is shown in Fig 1. The histopathologic diagnosis was performed according to the 2016 World Health Organization guidelines. ${ }^{24}$

\section{Surgical Treatment with PDT}

Patients who were scheduled for PDT received a single intravenous injection of talaporfin sodium (Laserphyrin; Meiji Seika 


\section{Patient characteristics}

\begin{tabular}{|c|c|c|c|}
\hline Characteristic & $\begin{array}{c}\text { PDT } \\
(n=14)\end{array}$ & $\begin{array}{l}\text { Non-PDT } \\
(n=10)\end{array}$ & $P$ Value \\
\hline Age (yr) & & & .98 \\
\hline Median (range) & $61.5(35-70)$ & $61.0(36-72)$ & \\
\hline Sex (No.) (\%) & & & .92 \\
\hline Male & $8(57)$ & $6(60)$ & \\
\hline Female & $6(43)$ & $4(40)$ & \\
\hline $\begin{array}{l}\text { Preoperative Karnofsky Performance } \\
\text { Status Scale score }\end{array}$ & & & .17 \\
\hline Median (range) & $80(30-100)$ & $70(30-100)$ & \\
\hline Tumor locations (No.) (\%) & & & .67 \\
\hline Frontal & $9(64)$ & $5(50)$ & \\
\hline Temporal & $3(21)^{\prime}$ & $4(40)$ & \\
\hline Parietal & $1(7)$ & $1(10)$ & \\
\hline Basal ganglia & $1(7)$ & $0(0)$ & \\
\hline Preoperative tumor volume $\left(\mathrm{cm}^{3}\right)$ & & & .07 \\
\hline Median (range) & $31.7(2.2-140.0)$ & $70.3(16.4-153.5)$ & \\
\hline Extent of resection (No.) (\%) & & & .91 \\
\hline Gross-total & $10(71)$ & $7(70)$ & \\
\hline Subtotal & $2(14)$ & $1(10)$ & \\
\hline Partial & $2(14)$ & $2(20)$ & \\
\hline Histopathology (No.) (\%) & & & .14 \\
\hline Glioblastoma & $11(79)$ & $10(10)$ & \\
\hline Anaplastic astrocytoma & $1(7)^{\prime}$ & $0(0)$ & \\
\hline Anaplastic oligodendroglioma & $2(14)$ & $0(0)$ & \\
\hline $\begin{array}{l}\text { Isocitrate dehydrogenase mutation } \\
\text { status (No.) (\%) }\end{array}$ & & & .50 \\
\hline Wild-type & $11(79)$ & $9(90)$ & \\
\hline Mutant & $3(21)$ & $1(10)$ & \\
\hline MIB-1 index & & & .65 \\
\hline Median (range) & $20(10-80)$ & $20(8-40)$ & \\
\hline
\end{tabular}

Pharma, Tokyo, Japan) at a dose of $40 \mathrm{mg} / \mathrm{m}^{2} 22-26$ hours before the operation. After maximum resection of the enhanced lesion, the entire resection cavity was irradiated with a 664-nm semiconductor laser (PD laser; Meiji Seika Pharma, Tokyo, Japan) (diameter, $1.5 \mathrm{~cm}$; radiation power density, $150 \mathrm{~mW} / \mathrm{cm}^{2}$; radiation energy density, $27 \mathrm{~J} / \mathrm{cm}^{2}$ ). Each irradiation was performed for 3 minutes per spot without overlap of the previously irradiated area and without limitation of the number of irradiation spots. The canopy walls were irradiated by reflecting the beam using a mirror. The large blood vessels were protected by aluminum foil so as not to be directly irradiated. Post-therapeutic light protection $(<500$ lux $)$ was performed for 10-14 days to prevent photosensitive dermatosis.

\section{Imaging Analysis}

DWI was performed with a $3 \mathrm{~T} \mathrm{MR}$ imaging scanner (Achieva; Philips Healthcare, Best, the Netherlands) using echo-planar imaging and the

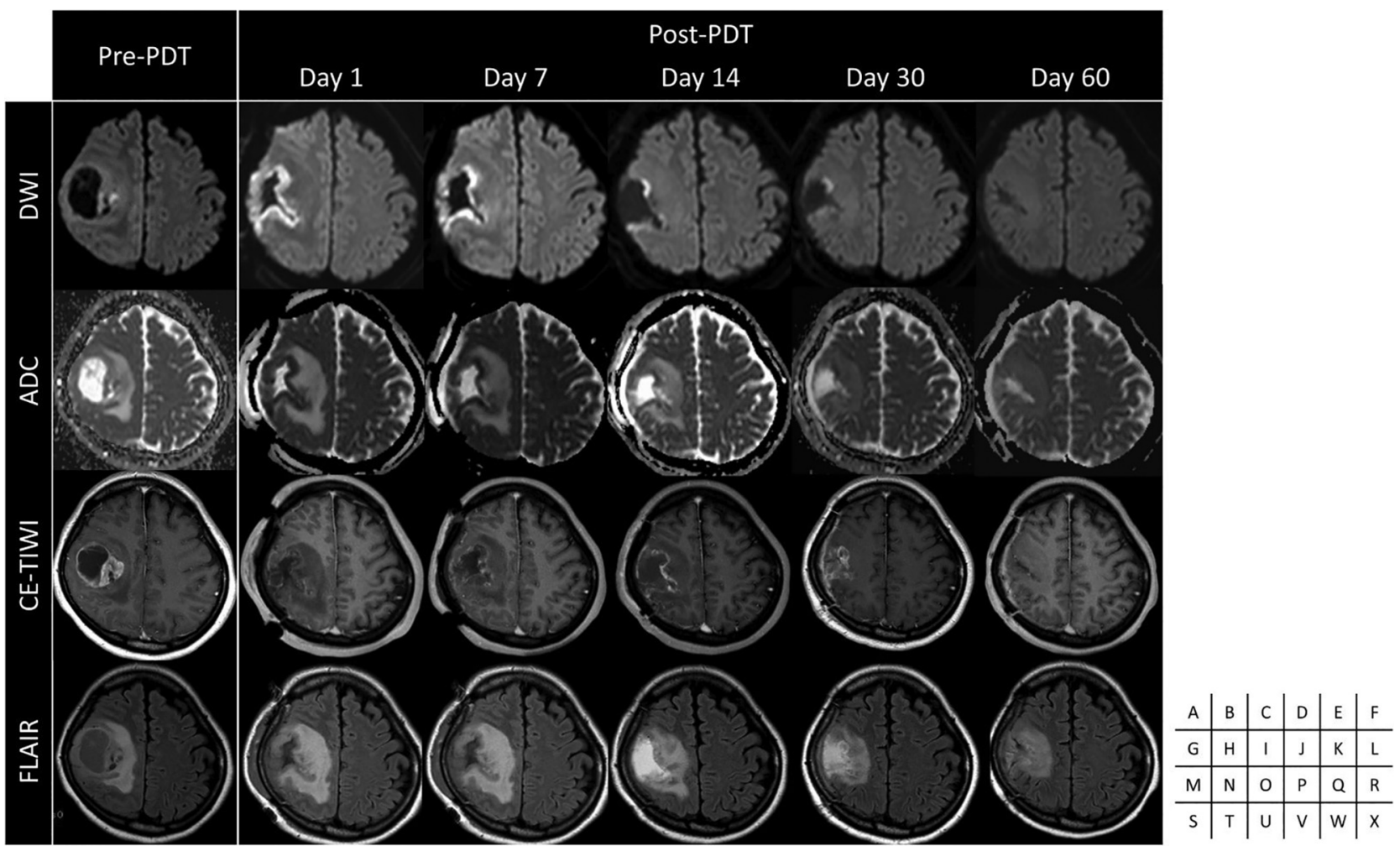

FIG 2. A representative case in the PDT group. Preoperative DWI (A), ADC map (G), CE-TIWI (M), and FLAIR (S) demonstrate the lesion with a cyst in the right frontal lobe. Postoperative DWI $(B-F)$, ADC map $(H-L), C E-T W W(N-R)$, and FLAIR $(T-X)$ show time-dependent changes after PDT. 


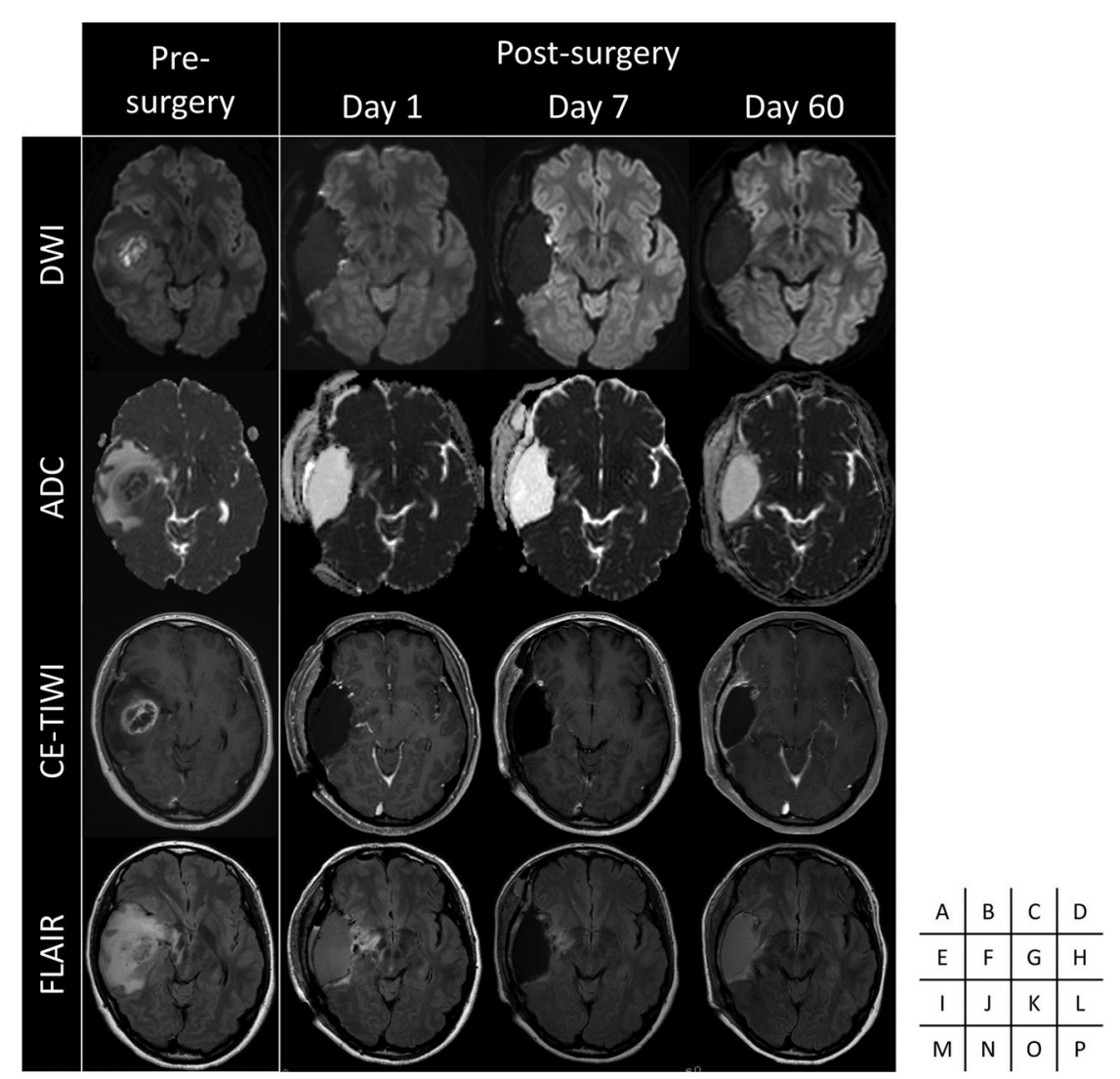

FIG 3. $A$ representative case in the non-PDT group. Preoperative DWI $(A), A D C$ map $(E), C E-T I W I$ $(I)$, and FLAIR $(M)$ demonstrate the lesion in the right temporal lobe. Postoperative DWI $(B-D)$, ADC map $(F-H)$, CE-TTWI $(l-L)$, and FLAIR $(N-P)$ show time-dependent changes after the operation.

following parameters: b-values, 0 and $1000 \mathrm{~s} / \mathrm{mm}^{2}$; TR/TE, 4500/ $75 \mathrm{~ms}$; FOV, $240 \mathrm{~mm}$; section thickness, $4 \mathrm{~mm}$; section gap, $1 \mathrm{~mm}$; matrix, $109 \times 128$; and flip angle, $90^{\circ}$. The ADC values from DWI of 2 types (b-values, 0 and $1000 \mathrm{~s} / \mathrm{mm}^{2}$ ) were calculated per voxel to create the ADC map. An ROI measuring 10-20 $\mathrm{mm}^{2}$ was drawn manually on a representative DWI section of the largest resection cavity and was set on the PDT-irradiated area in the PDT group and on the surgical resection margin in the nonPDT group. The ROI was then reflected to the ADC map. To assess time-dependent changes, we set ROIs numbered 1-5, respectively, with a wide and balanced distribution and followed them at the same anatomic locations. The mean of the ADC values within the ROIs was used for statistical analysis. The ROIs were drawn by a single neurosurgeon (Y.F.) and confirmed by another neurosurgeon (T.S.).

The conventional MR imaging sequences included FLAIR (TR/ TE/TI, 4500/148/1600 ms; FOV, 240 mm; matrix, $240 \times 240$; section thickness, $1.0 \mathrm{~mm}$ ) and 3D T1WI (TR/TE/TI, 6.4/2.8/1200 ms; FOV, $260 \mathrm{~mm}$; matrix, $320 \times 320$; section thickness, $0.8 \mathrm{~mm}$ ) before and after injection of the intravenous gadolinium contrast agent $(0.2 \mathrm{~mL} / \mathrm{kg}$, Magnescope; Meglumine gadoterate, Guerbet, Paris, France).

\section{Statistical Analysis}

The characteristics of each group were compared using the Fisher exact test and the Mann-Whitney $U$ test. The Friedman test was used to assess the postoperative timedependent change in ADC values. The Bonferroni test was used for post hoc comparisons. The Mann-Whitney $U$ test was used to compare ADC values between the groups. All statistical analyses were performed with EZR (Saitama Medical Center, Jichi Medical University, Saitama, Japan), which is a graphic user interface for R statistical and computing software (http://www.r-project. org/). ${ }^{25}$ A 2 -sided $P$ value of $<.05$ was considered statistically significant.

\section{RESULTS}

\section{Patient Characteristics}

In total, 24 patients were included in the study. There were 14 patients ( 8 men, 6 women; median age, 61.5 years [range, 35-70 years]) in the PDT group and 10 patients (6 men, 4 women; median age, 61.0 years [range, 36-72 years]) in the non-PDT group (Fig 1). The characteristics of the patients in both groups are summarized in the Table. There were no statistically significant between-group differences in age, sex, preoperative Karnofsky Performance Status Scale score, tumor location, preoperative tumor volume, or extent of resection at baseline. Intraoperative MR imaging was performed in 12 patients $(86 \%)$ in the PDT group and $8(80 \%)$ in the non-PDT group. In the PDT group, all 12 patients who underwent intraoperative MR imaging had no evidence of surgery-related ischemia or hemorrhage before PDT. Awake surgery was performed in 1 (7\%) of the patients in the PDT group and 3 (30\%) of those in the non-PDT group because the tumors were close to the Broca area. There was no statistically significant difference in histology, isocitrate dehydrogenase status, or the MIB-1 index between the 2 groups. The median number of irradiation spots was 13 (range, $5-31$ ) in the PDT group. No patient in either group showed neurologic deterioration postoperatively or a deterioration in Karnofsky Performance Status Scale score at 60 days.

\section{Post-PDT MR Imaging}

In all patients in the PDT group, linear high signals on DWI in the irradiated area were detected adjacent to the resection cavity and were 5-7 $\mathrm{mm}$ in depth from 1 day posttreatment and disappeared in about 30 days without any neurologic deterioration (Fig 2). The area on the ADC map corresponding to the high signals on DWI was hypointense. None of the patients in the nonPDT group showed this change (Fig 3).

These changes in DWI were also tracked by the ADC value. The PDT group had lower ADC values from 1 day after PDT. The ADC values (expressed as $10^{-6} \mathrm{~mm}^{2} / \mathrm{s}$ ) increased in a timedependent manner, continued to increase significantly up to 

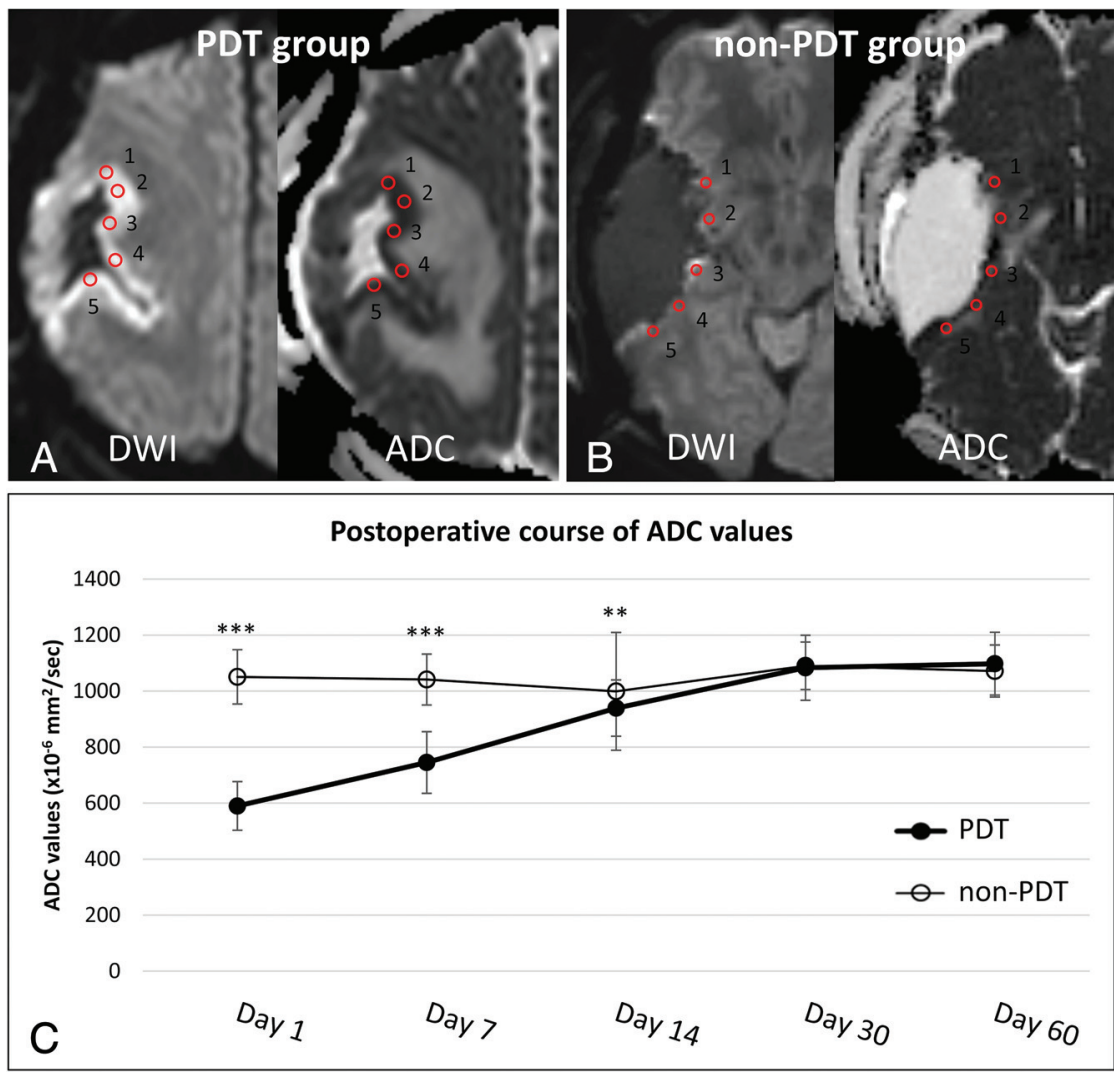

FIG 4. Postoperative DWI (left) and ADC map (right) demonstrate representative settings for the ROIs in the PDT group (A) and non-PDT group (B). The small circles labeled 1-5 indicate the ROls used for analysis of the ADC values. A line graph demonstrates the postoperative time-dependent change in ADC values in the PDT group (thick line) and non-PDT group (thin line) (C). Double asterisks indicate $P<.01$; triple asterisks, $P<.001$, Mann-Whitney $U$ test.

\section{DISCUSSION}

Surgery combined with PDT is a novel localized treatment for malignant glioma that can selectively kill tumor cells invading from the surgical resection margin to the peripheral normal brain. Previous studies have demonstrated its safety and effectiveness. ${ }^{18,19,26}$ PDT with talaporfin sodium, a second-generation photosensitizer, has been safely used in patients with malignant glioma at our institution since August 2017. In this study, we identified specific changes on MR imaging scans that can be used to monitor the early response to PDT. The PDT-irradiated site showed linear high signals of $5-7 \mathrm{~mm}$ on DWI from the acute phase after PDT that were transient and asymptomatic. Furthermore, the high signals on DWI had concurrently lower ADC values, which improved in a time-dependent manner parallel to the signal intensity on DWI.

DWI is an MR imaging sequence that images the Brownian motion of water molecules in tissue. The ADC is less susceptible to T2 shinethrough, which is a problem with DWI, and accurately reflects the diffusivity of water molecules. Cellular swelling and 30 days after PDT (589.8 \pm 86.7 on day $1 ; 745.1 \pm 109.9$ on day 7 , $939.1 \pm 100.3$ on day 14 , and $1083.2 \pm 116.2$ on day $30 ; P<.001)$, and reached a plateau $(1097.6 \pm 112.2$ on day $60 ; P=1.0$, Fig 4$)$. In contrast, there was no decline and time-dependent change in ADC values after the operation in the non-PDT group (1050.8 \pm 96.9 on day $1,1041.2 \pm 91.0$ on day $7,998.8 \pm 210.3$ on day 14 , $1090.4 \pm 84.7$ on day 30 , and $1071.5 \pm 92.8$ on day $60 ; P=.44$, Fig 4). The ADC values in the PDT group were significantly lower than those in the non-PDT group until 14 days after the operation; thereafter, the difference was no longer statistically significant (day $1, P<.001$; day $7, P<.001$; day $14, P=.002$; day $30, P=.33$; and day $60, P=.36$; Fig 4 ).

One patient in the PDT group had both PDT-irradiated and nonirradiated areas because the middle cerebral artery ran through the center of the resected cavity. In this case, the nonirradiated area showed neither high signal on DWI nor a decline in the $\mathrm{ADC}$ value. $\mathrm{ADC}$ values in the nonirradiated area remained in the range of $1000-1200 \times 10^{-6} \mathrm{~mm}^{2} / \mathrm{s}$ from day 1 to day 60 after the operation with PDT (Fig 5).

On CE-T1WI, all patients in both groups showed thin linear contrast effects along the resected cavity wall at 1-2 weeks after the operation. Fluid retention was observed on FLAIR in 9 patients (64\%) in the PDT group and 7 (70\%) of those in the non-PDT group. The difference between the 2 groups was not statistically significant $(P=.56)$. narrowing of the extracellular space due to effects of cytotoxicity such as ischemia, known as cytotoxic edema, restrict the movement of water. ${ }^{21,23}$ In general, regions with cell damage show high signals on DWI and low ADC values.

Three main mechanisms are known to underpin the effect of PDT: 1) direct tumor cell killing including apoptosis and necrosis, $^{26,27}$ 2) tumor-associated vascular damage, ${ }^{28,29}$ and 3) activation of the immune response against tumor cells. ${ }^{30-32}$ These cannot be attributed to the photosensitizer alone or the laser alone. $^{35,36}$ The photosensitizer used in PDT is transformed from its ground state into an electronically excited state by laser light of a specific wavelength and transfers the energy directly to triplet oxygen to form singlet oxygen (a type II reaction), which exerts an antitumor effect. ${ }^{4}$ We could capture the PDT-induced early response as high signals on DWI and low ADC values because the cell damage and microcirculatory impairment caused by PDT led to restricted diffusivity of water molecules. These changes in DWI and ADC values were observed only in the PDT-irradiated area and not in the nonirradiated area, even in the same patient.

Furthermore, the tissue transmittance of the laser depends on the wavelength and irradiation power. The semiconductor laser used in this study $\left(664 \mathrm{~nm}, 150 \mathrm{~mW} / \mathrm{cm}^{2}\right)$ has been reported to penetrate to an approximate tissue depth of $5 \mathrm{~mm} .{ }^{19}$ The match of the width of the DWI high signal and the depth of penetration mechanisms also influence each other. ${ }^{33,34}$ The antitumor effects 

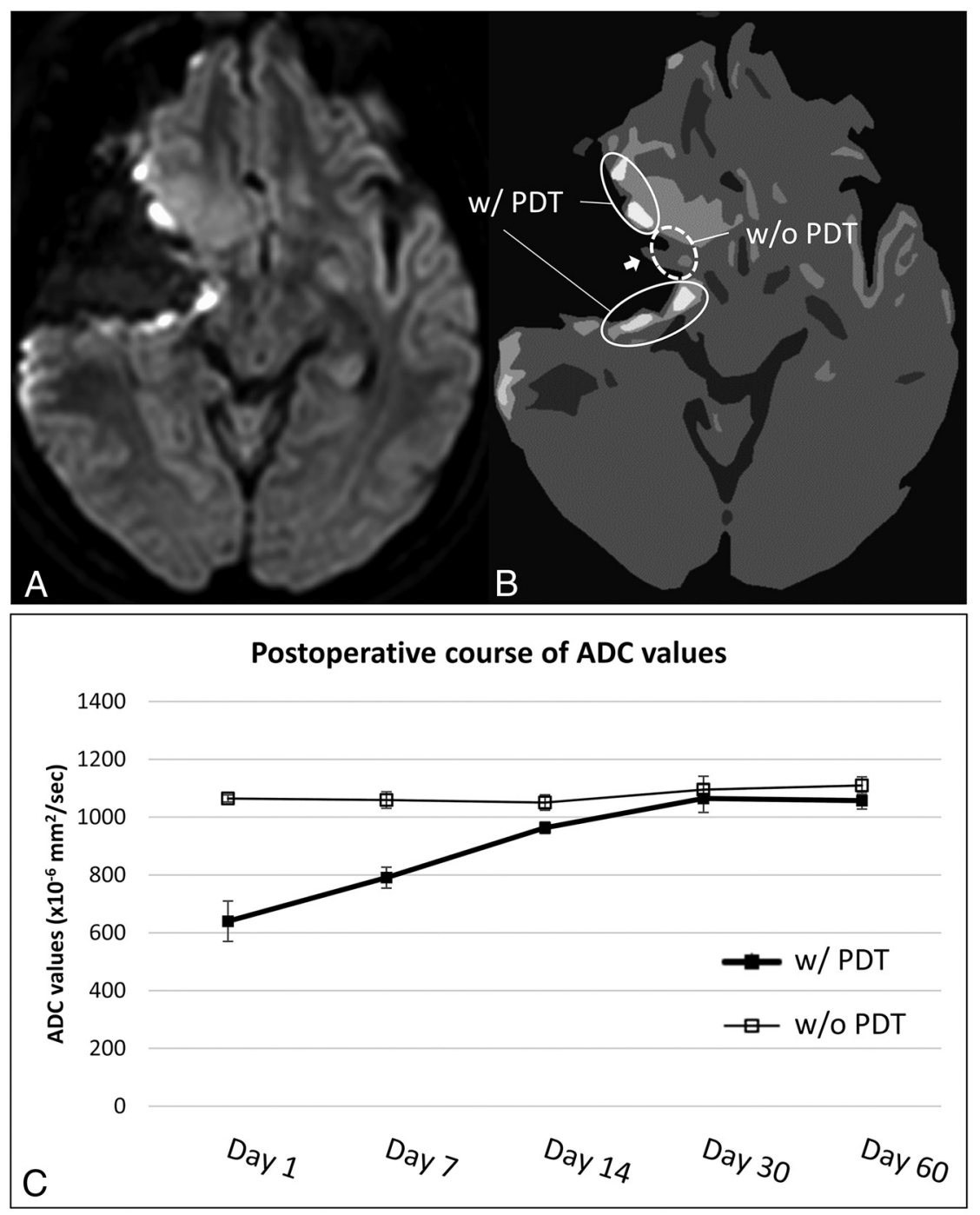

FIG 5. DWI $(A)$ and a schematic illustration of $A(B)$ show the post-PDT changes in irradiated and nonirradiated areas on day 1 for 1 patient in the PDT group. The circle with the solid line indicates the area with PDT irradiation (w/PDT). The circle with the dotted line indicates the area without PDT irradiation (w/o PDT). The white arrow indicates the middle cerebral artery. The line graph shows the postoperative time-dependent changes in ADC values in areas with PDT (thick line) and without PDT (thin line) (C).

of the laser strongly suggests that the abnormal findings on DWI and ADC were caused by the effect of PDT. Although the level and postoperative course of the ADC values in the PDT group were similar to those in ischemic stroke, the initial recovery of the ADC values was found to be more rapid after PDT than after stroke. ${ }^{23}$ Moreover, all the changes in DWI and ADC values in the PDT group were asymptomatic in this study. PDT is able to attack only tumor cells with accumulated photosensitizer while preserving the surrounding normal brain cells without a bystander effect because singlet oxygen has a short migration distance of $0.02-1 \mu \mathrm{m}$ and a short lifetime in the range of $0.04-4 \mu \mathrm{s} .{ }^{37,38}$ Therefore, the asymptomatic nature of our findings on DWI and ADC further supports our hypothesis.

The other abnormalities seen on CE-T1WI and FLAIR were similar to those reported previously ${ }^{19,20}$ and could not be used to distinguish between the PDT and non-PDT groups. These findings were transiently observed in the subacute phase after the operation but not in the acute phase, which might reflect inflammation and immunoreactivity after surgery and PDT.

In summary, our findings suggest that a linear high signal on DWI accompanied by a decline in ADC values after PDT are purely PDT-induced MR imaging changes. Although PDTinduced MR imaging changes on DWI and in ADC values are transient and disappear by around 30 days, they seem to be useful for confirming the PDT-irradiated area. To our knowledge, this is the first study to show the usefulness of DWI and ADC values for monitoring the PDT-induced acute response of malignant glioma. However, our study also had several limitations. First, the number of patients treated with PDT was small. Second, the study was conducted at a single institution. Third, the ROIs for the ADC values reflected some but not all of the regions in which PDT was suspected to have had an effect. Fourth, surgery-related changes before PDT were not confirmed intraoperatively in 2 of the 14 patients in the PDT group. Finally, this study could not fully examine the utility of DWI and ADC values when monitoring recurrence and progression after PDT because the follow-up time was relatively short. Six of 14 patients in the PDT group experienced tumor recurrence, and only 3 patients exhibited local recurrence during follow-up. In contrast, all patients in the non-PDT group had recurrence, which was local in 6 patients. Most interesting, all the local recurrences in the PDT group arose from the nonirradiated area, which did not show a high signal on DWI. Further studies are needed to clarify the association of our findings with pathologic mechanisms and their long-term impact. Nevertheless, findings that the visually apparent changes on DWI and the change in ADC values were consistent across all PDT patients in this study are clinically worthwhile.

\section{CONCLUSIONS}

This study provided new evidence that the acute response of malignant glioma to PDT could be detected as linear high signals on DWI and a decline in ADC values that were asymptomatic and transient. These linear high signals on DWI may be useful for confirming the PDT-irradiated area. 


\section{ACKNOWLEDGMENTS}

We thank Miss Takiko Uno for molecular analysis of the isocitrate dehydrogenase mutation status of patients in this study.

Disclosures: Yuich Fujita_RELATED: Grant: Grant-in-Aid for Scientific Research (KAKENHI) from the Japanese Ministry of Education, Culture, Sports, Science and Technology, Comments: 17K10864, 17K10863.* Eiji Kohmura-UNRELATED: Grants/ Grants Pending: Takeda Pharmaceutical Company, Sanofi, Chugai Pharmaceutical Company, Pfizer, Comments: academic contributions*; Payment for Lectures Including Service on Speakers Bureaus: Olympus, Comments: honorarium. *Money paid to the institution.

\section{REFERENCES}

1. Stupp R, Mason WP, van den Bent MJ, et al. Radiotherapy plus concomitant and adjuvant temozolomide for glioblastoma. $\mathrm{N} \mathrm{Engl} \mathrm{J}$ Med 2005;352:987-96 CrossRef Medline

2. Konishi Y, Muragaki Y, Iseki H, et al. Patterns of intracranial glioblastoma recurrence after aggressive surgical resection and adjuvant management: retrospective analysis of $\mathbf{4 3}$ cases. Neurol Med Chir (Tokyo) 2012;52:577-86 CrossRef

3. Gaspar LE, Fisher BJ, Macdonald DR, et al. Supratentorial malignant glioma: Patterns of recurrence and implications for external beam local treatment. Int J Radiat Oncol 1992;24:55-57 CrossRef Medline

4. Henderson BW, Dougherty TJ. How does photodynamic therapy work? Photochem Photobiol 1992;55:145-57 CrossRef Medline

5. Raab O. Uber die wirkung Fluorescirender Stoffe auf Infusorien. $Z$ Biol 1900;39:524-46

6. Lipson RL, Baldesi EJ. The photodynamic properties of a particular hematoporphyrin derivative. Arch Dermatol 1960;82:508-16 CrossRef Medline

7. Lipson RL, Baldes EJ, Olsen AM. The use of a derivative of hematoporhyrin in tumor detection. J Natl Cancer Inst 1961;26:1-11 Medline

8. Hayata $\mathrm{Y}$, Kato $\mathrm{H}$, Konaka $\mathrm{C}$, et al. Hematoporphyrin derivative and laser photoradiation in the treatment of lung cancer. Chest 1982;81:269-77 CrossRef Medline

9. McCaughan JS, Hicks W, Laufman L, et al. Palliation of esophageal malignancy with photoradiation therapy. Cancer 1984;54:2905-10 CrossRef Medline

10. Hayata $\mathrm{Y}$, Kato $\mathrm{H}$, Okitsu $\mathrm{H}$, et al. Photodynamic therapy with hematoporphyrin derivative in cancer of the upper gastrointestinal tract. Semin Surg Oncol 1985;1:1-11 CrossRef Medline

11. Mang TS, Allison R, Hewson G, et al. A phase II/III clinical study of tin ethyl etiopurpurin (Purlytin)-induced photodynamic therapy for the treatment of recurrent cutaneous metastatic breast cancer. Cancer J Sci Am 1998;4:378-84 Medline

12. Ward BG, Forbes IJ, Cowled PA, et al. The treatment of vaginal recurrences of gynecologic malignancy with phototherapy following hematoporphyrin derivative pretreatment. Am J Obstet Gynecol 1982;142:356-57 CrossRef Medline

13. Schweitzer VG. Photodynamic therapy for treatment of head and neck cancer. Otolaryngol Head Neck Surg 1990;102:225-32 CrossRef Medline

14. Perria C, Capuzzo T, Cavagnaro G, et al. Fast attempts at the photodynamic treatment of human gliomas. J Neurosurg Sci 1980;24:11929 Medline

15. Stylli SS, Kaye AH, MacGregor L, et al. Photodynamic therapy of high-grade glioma: long-term survival. J Clin Neurosci 2005;12:38998 CrossRef Medline

16. Muller PJ, Wilson BC. Photodynamic therapy of brain tumors: a work in progress. Lasers Surg Med 2006;38:384-89 CrossRef Medline

17. Eljamel S. Photodynamic applications in brain tumors: a comprehensive review of the literature. Photodiagnosis Photodyn Ther 2010;7:76-85 CrossRef Medline

18. Muragaki Y, Akimoto J, Maruyama T, et al. Phase II clinical study on intraoperative photodynamic therapy with talaporfin sodium and semiconductor laser in patients with malignant brain tumors. J Neurosurg 2013;119:845-52 CrossRef Medline

19. Nitta M, Muragaki Y, Maruyama T, et al. Role of photodynamic therapy using talaporfin sodium and a semiconductor laser in patients with newly diagnosed glioblastoma. J Neurosurg 20181;1-8 CrossRef Medline

20. Sato N, Bronen RA, Sze G, et al. Postoperative changes in the brain MR imaging findings in patients without neoplasms. Radiology 1997;204:839-46 CrossRef Medline

21. Latchaw RE, Alberts MJ, Lev MH, et al. Recommendations for imaging of acute ischemic stroke: a scientific statement from the American Heart Association. Stroke 2009;40:3646-78 CrossRef Medline

22. Moseley ME, Cohen Y, Mintorovitch J, et al. Early detection of regional cerebral ischemia in cats: comparison of diffusion- and T2 weighted MRI and spectroscopy. Magn Reson Med 1990;14:330-46 CrossRef Medline

23. Huang I-J, Chen C-Y, Chung H-W, et al. Time course of cerebral infarction in the middle cerebral arterial territory: deep watershed versus territorial subtypes on diffusion-weighted MR images. Radiology 2001;221:35-42 CrossRef Medline

24. Louis DN, Perry A, Reifenberger G, et al. The 2016 World Health Organization classification of tumors of the central nervous system: a summary. Acta Neuropathol 2016;131:803-20 CrossRef Medline

25. Kanda Y. Investigation of the freely available easy-to-use software “EZR” for medical statistics. Bone Marrow Transplant 2013;48:45258 CrossRef Medline

26. Akimoto J. Photodynamic therapy for malignant brain tumors. Neurol Med Chir (Tokyo) 2016;56:151-57 CrossRef Medline

27. Henderson BW, Waldow SM, Mang TS, et al. Tumor destruction and kinetics of tumor cell death in two experimental mouse tumors following photodynamic therapy. Cancer Res 1985;45:57276 Medline

28. Fingar VH, Wieman TJ, Haydon PS. The effects of thrombocytopenia on vessel stasis and macromolecular leakage after photodynamic therapy using photofrin. Photochem Photobiol 1997;66:51317 CrossRef Medline

29. Ferrario A, von Tiehl KF, Rucker N, et al. Antiangiogenic treatment enhances photodynamic therapy responsiveness in a mouse mammary carcinoma. Cancer Res 2000;60:4066-69 Medline

30. Shumaker BP, Hetzel FW. Clinical laser photodynamic therapy in the treatment of bladder carcinoma. Photochem Photobiol 1987 46:899-901 CrossRef Medline

31. de Vree WJ, Essers MC, de Bruijn HS, et al. Evidence for an important role of neutrophils in the efficacy of photodynamic therapy in vivo. Cancer Res 1996;56:2908-11 Medline

32. Gollnick SO, Liu X, Owczarczak B, et al. Altered expression of interleukin $\mathbf{6}$ and interleukin 10 as a result of photodynamic therapy in vivo. Cancer Res 1997;57:3904-09 Medline

33. Dolmans D, Fukumura D, Jain RK. Photodynamic therapy for cancer. Nat Rev Cancer 2003;3:380-87 CrossRef Medline

34. Castano AP, Mroz P, Hamblin MR. Photodynamic therapy and antitumour immunity. Nat Rev Cancer 2006;6:535-45 CrossRef Medline

35. Fujiwara Y, Miki Y, Akimoto J, et al. Effect of talaporfin sodiummediated photodynamic therapy on cell death modalities in human glioblastoma T98G cells. J Toxicol Sci 2014;39:821-27 CrossRef Medline

36. Ohashi S, Kikuchi O, Tsurumaki M, et al. Preclinical validation of talaporfin sodium-mediated photodynamic therapy for esophageal squamous cell carcinoma. PLoS One 2014;9:e103126 CrossRef Medline

37. Moan J, Berg K. The photodegradation of porphyrins in cells can be used to estimate the lifetime of singlet oxygen. Photochem Photobiol 1991;53:549-53 CrossRef Medline

38. Stylli SS, Kaye AH. Photodynamic therapy of cerebral glioma: a review, Part I: a biological basis. J Clin Neurosci 2006;13:615-25 CrossRef Medline 